\title{
The Reasons for the Decline of the Results of Jordanian Students in "TIMSS 2015"
}

\author{
Khaled Abu Tayeh \\ Dr., Al-Hussien bin Talal University, Jordan
}

Mohammad S. Al-Rsa'i

Dr., Al-Hussien bin Talal University, Jordan, rsaaie@ahu.edu.jo

\section{Mohammad F. Al-Shugairat}

Education Ministry, Jordan

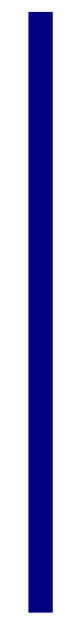

The study aimed at identifying the reasons behind the Jordanian students' drop of performance in the TIMSS 2015 from the point of view of their teachers. Survey method was used because teachers are the most able to decide upon the reasons of this fall and so a questionnaire was designed to recognize their point of view concerning the reasons of this retreat. The study population consisted of 130 teachers of science and mathematics in Ma'an governorate. Teachers whose teaching experience was more than one year to make sure they are familiar with TIMSS tests. Random sampling technique was used to select 90 teachers representing $69 \%$ of the study population. For data analysis, means and standards deviations were calculated, and the Schiffe test was used to determine the post differences. The results show that the reasons related to the students themselves and their families got higher averages than those related to the teachers and the curricula. The averages related to the male teachers are also higher than those related to the female teachers. There are no statistical differences in the teachers' appreciation averages of the reasons of this retreat according to their academic specialization (math or science) or their practical experience.

Keywords: learning evaluation, teaching science and math, curriculum, TIMSS 2015, teacher's preceptions, Jordan

\section{INTRODUCTION}

The results of international assessment studies gain great importance among most countries of the world; they represent an indication of the real state of education in any state providing an overview of the future of the economy of this state, as well as, all areas of development. Therefore, most countries of the world are keen to score advanced ranks in these studies (Hanushek, Peterson \& Woessmann, 2010), and great 
efforts are being made to develop students' abilities and skills to achieve high marks (Robinson, Lloyd \& Rowe, 2008). The importance of these studies is that they provide feedback and global substantive assessments of performance of the levels of students. (Abu Libda, 2008).

TIMSS (Trends in International Mathematics and Science Study) is one of these comparative studies, which aims at measuring the attitudes and abilities of fourth and eighth graders in science and mathematics. TIMSS study is supervised by IEA foundation (The International Association for the Evaluation of Educational Achievement) and is implemented every four years (Shi, et al., 2016). The Hashemite Kingdom of Jordan has participated in TIMSS study since the second session held in 1999, while the first session was in 1995. The results of the Jordanian students were distinct compared to the countries of the region and the Middle East, but it started to witness a significant decline in recent sessions (Samida \& Grace, 2014).

Jordanian students' achievement in mathematics has declined 20 degrees between TIMSS 2011 and TIMSS 2015 and 23 degrees in science (Mullis, Martin \& Loveless, 2016). Therefore, it was greatly important to search for the causes of this poor performance for the sake of correction. This will help the Jordanian administrators of the educational process to reform public education, based on the scientific and substantive foundations of measurement and evaluation procedures.

Jordan depends mainly on human resources as it is one of the poorest countries in the world in water, energy, and other resources. This has led Jordanian government to be interested in education at all stages to ensure the achievement of high level of educational product. Thus, the Jordanian government has achieved a clear success in its objectives in this field, and Jordan students achieved advanced levels in most of the regional and global tests, especially the TIMSS study, which deals with the measurement of abilities in the field of science and mathematics.

This distinction has affected various areas of development and the indicators of the national economy have significantly increased. However, in recent years we have seen a decline in the results of Jordan's students in the same international tests, which raised fears of Jordanian citizens and the managers of human resources. It was necessary to search for the causes of this decline and to look for the appropriate treatment of the Jordanian Educational system.

As we know, the teachers are the most familiar with the details of the educational process and its variables. In addition, they are the most able to determine the factors affecting the levels and quality of the educational product. Thus, the current study has sought to determine the reasons for the decline of the results of Jordanian students in TIMSS global tests, and identify the most influential reasons and make recommendations in this regard. Therefore, the study will answer the following questions:

1. What are the reasons for the decline of Jordan's students in the TIMSS test from the teachers' point of view? 
2. Are there any statistically significant differences in teachers' perceptions of the reasons for the decline in performance of the Jordanian students in the TIMSS test according to a range of variables?

\section{LITERATURE REVIEW:}

Teaching science and mathematics is important to those involved in education because of its role in providing students with many skills of thinking and solving problems and the impact of this on successful life (Mullis et al., 2012).

The TIMSS2015 study therefore focuses on the assessment of necessary skills in science and mathematics within high standards based on previous TIMSS sessions where a team of experts (TIMSS National Research Coordinators) develops and updates the new version of the tests to taking into account the characteristics of the educational process in all countries of the world. This team includes representatives from all countries participating in the study (Ker, 2013; Mullis \& Martin, 2013).

The TIMSS Assessment is a general approach to assessing knowledge, skills and attitudes that reflect current changes in educational curricula. In addition, it uses an evaluation method that measures students' ability to use knowledge in daily life situations they face at school, at home, and in society. The skills that are measured relate to the ability of students to learn lifelong learning by applying what they have learned in school to new life situations, such as evaluating their choices and making decisions. TIMSS study focuses on assessing what students can do compared to what they have learned. The study also aims at comparing the levels of students in the world, revealing their shortcomings, and enabling developing countries to benefit from the experience of advanced countries.

The TIMSS study relies on two types of tools (Mullis \& Martin, 2013):

(1) Cognitive tests to assess students' performance in science and mathematics consisted of different groups within the following subjects in mathematics: Number, Algebra, Geometric Shapes and Measures, Data Display, and probabilities as it is indicated in Table (1) . In the field of science, students are tested in Biology, Chemistry, Physics and Earth Science subjects as shown in Table (2).

(2) The second assessment tool was the questionnaires for collecting information about the learning environment directly related to the learning of Mathematics and Science. The first questionnaire was dedicated to students and designed in two versions - fourth and eighth grades students. The second questionnaire was dedicated to teachers and designed in three versions - teachers of science, teacher of mathematics and the teachers of the two disciplines together. The third was the school principal questionnaire.

Table 1

Target percentages of the TIMSS 2015 mathematics assessment devoted to content and cognitive domains at the fourth and eighth grades

\begin{tabular}{lc}
\hline Fourth Grade & \\
\hline Content Domains & Percentages \\
\hline Numbers & $50 \%$ \\
\hline
\end{tabular}




\begin{tabular}{|c|c|c|}
\hline Geometric Shapes and Measures & \multicolumn{2}{|c|}{$35 \%$} \\
\hline Data Display & \multicolumn{2}{|c|}{$15 \%$} \\
\hline Eighth Grade & & \\
\hline Content Domains & \multicolumn{2}{|c|}{ Percentages } \\
\hline Numbers & \multicolumn{2}{|c|}{$30 \%$} \\
\hline Algebra & \multicolumn{2}{|c|}{$30 \%$} \\
\hline Geometry & \multicolumn{2}{|c|}{$20 \%$} \\
\hline Data and Chance & \multicolumn{2}{|c|}{$20 \%$} \\
\hline Cognitive Domains & Fourth Grade & Eighth Grade \\
\hline Knowing & $40 \%$ & $35 \%$ \\
\hline Applying & $40 \%$ & $40 \%$ \\
\hline Reasoning & $20 \%$ & $25 \%$ \\
\hline
\end{tabular}

Table 2

Target percentages of the TIMSS 2015 science assessment devoted to content and cognitive domains at the fourth and eighth grades

\begin{tabular}{|c|c|}
\hline Fourth Grade & \\
\hline Content Domains & Percentages \\
\hline Life Science & $45 \%$ \\
\hline Physical Science & $35 \%$ \\
\hline Earth Science & $20 \%$ \\
\hline \multicolumn{2}{|l|}{ Eighth Grade } \\
\hline Content Domains & Percentages \\
\hline Biology & $35 \%$ \\
\hline Chemistry & $20 \%$ \\
\hline Physics & $25 \%$ \\
\hline Earth Science & $20 \%$ \\
\hline Cognitive Domains & $\begin{array}{ll}\text { Fourth Grade } \quad \text { Eighth Grade } \\
\end{array}$ \\
\hline Knowing & $40 \%$ \\
\hline Applying & $35 \%$ \\
\hline Reasoning & $30 \%$ \\
\hline
\end{tabular}

A number of fundamental factors influence the results of students in the TIMSS study (as it is the case in any measurement process). These factors are: the student's own abilities, knowledge, and skills, in addition to his interests and motives toward learning, which occupy the prior rank of the list of these factors (Wigfield \& Eccles, 2002). Studies in this field have shown that students' familiarity with questions that require higher levels of thinking contributes significantly to their performance in the assessment process, but the process of evaluation in learning science and mathematics in particular depends on the student's accumulated experience acquired in previous periods (Chang, Singh \& Mo, 2007), and it is also affected by families' interests and meeting their children's needs (Hojo \& Oshio, 2010). The requirements for successful learning also have an impact on their scores and their achievement in tests (Jaafari, 2010; Al-Ghamdi, 2010).

The second factor that influences the results of the students' evaluation and performance is the teacher and his teaching experience and deep knowledge of the content of the 
subject matter. (Hill, Rowan \& Ball, 2005; Chetty, Friedman \& Rockoff, 2014). This requires the instructor to assist his students in obtaining outstanding results in the national and international tests by being anxious to know how to build the tests, formulate its questions and manage their applications (Fuchs \& Woessmann, 2004).

The third factor that influences the results of the students' evaluation and performance is the curriculum; how it is planned, the nature of its scientific content, curriculum activities and how it is implemented in the classroom (Roseth, Johnson \& Johnson, 2008). Teaching sciences and mathematics requires designing activities that develop learners 'higher order skills. Furthermore, the nature of the evaluation activities in the curriculum affects the performance and achievement of students, taking into account the varying levels of questions that require different thinking skills.

Therefore, the countries of the world are interested in obtaining advanced results in the international tests, especially the TIMSS tests by controlling the three factors influencing the results. This research aims at revealing the vision of the science and mathematics teachers in Jordan of the most influential factors that affected the results of their students in TIMSS study, hence the importance of this study rises from its impact on addressing the decline in the performance of Jordanian students and their levels among the students of the rest of the world.

\section{METHOD}

\section{Population and Sample}

The study used the descriptive survey method to achieve the required objectives. The study population consisted of 130 teachers of science and mathematics in Ma'an governorate, one of the big provinces in Jordan. Teachers whose teaching experience was more than one year to make sure they are familiar with TIMSS tests. Random sampling technique was used to select 90 teachers representing $69 \%$ of the study population as it illustrated in table 3 .

Table 3

Distribution of the Study Sample Members

\begin{tabular}{llll}
\hline \multirow{2}{*}{ Gender } & \multicolumn{2}{c}{ Specialty } & Total \\
\cline { 2 - 3 } & Science & Math & \\
\hline Male & 14 & 17 & 31 \\
\hline Female & 27 & 32 & 59 \\
\hline Total & 41 & 49 & 90 \\
\hline
\end{tabular}

\section{Instrument}

After exploring the reasons that lead to the decline in student performance on the TIMSS test and the aid of related studies, these reasons revolved around three areas: teacher, curriculum, student and family. To verify the validity and reliability of the instrument, the draft instrument was presented to five specialists in the teaching of science and mathematics and their suggestions were collected and according to these suggestions the tool was modified to be 29 items divided into three areas as shown in Table 4. 
Table 4

Domains of Study Instrument and Number of Items

\begin{tabular}{ll}
\hline Domain & Number of items \\
\hline Reasons related to the teacher & 13 \\
\hline Reasons related to the curriculum & 8 \\
\hline Reasons related to student and family & 8 \\
\hline Total & 29 \\
\hline
\end{tabular}

The researchers calculated the coefficient of reliability of the instrument by means of the test-retest approach. They calculated the reliability coefficient between the pre and post applications. This process involved 17 teachers from outside the sample and the reliability coefficient was suitable at $(0.86)$. The internal consistency coefficient of the instrument and its domains were also calculated as it is shown in table 5.

Table 5

Internal Consistency Coefficients of the instrument.

\begin{tabular}{ll}
\hline Domain & Reliability coefficient \\
\hline Reasons related to the teacher & 0.86 \\
\hline Reasons related to the curriculum & 0.81 \\
\hline Reasons related to student and family & 0.85 \\
\hline Total & 0.83 \\
\hline
\end{tabular}

\section{FINDINGS}

Reasons for the decline in Jordanians students' performance in the TIMSS 2015 study

The study aimed at identifying the reasons behind the drop of the Jordanian students' performance in the TIMSS test from the point of view of their teachers. The results of the questionnaire prepared for this purpose were analyzed and presented according to the three domains (teacher, curriculum, student and family). The performance of students in the TIMSS test is rating as follows: $(1$ - 2.33) Poor $(2.34$ - 3.67) Medium (3.68 - 5) High, the following tables show these results: 


\section{Reasons Related to the Teacher}

Table 6

Statistical averages and standard deviations of sample estimates study in the theme of causes related to the teacher

\begin{tabular}{|c|c|c|c|c|}
\hline Item & The first theme: Teacher & Score & standard deviation & mean \\
\hline 1 & I have a sufficient knowledge about TIMSS tests. & Medium & 612 & 3.71 \\
\hline 2 & $\begin{array}{l}\text { I give students examples and models similar to the TIMSS } \\
\text { test pattern. }\end{array}$ & Medium & .872 & 3.60 \\
\hline 3 & $\begin{array}{l}\text { I use questions which simulate TIMSS questions in } \\
\text { students' assessment }\end{array}$ & Medium & .915 & 3.49 \\
\hline 4 & $\begin{array}{l}\text { I train students at additional times to deal with questions } \\
\text { similar to TIMSS. }\end{array}$ & Medium & 1.017 & 3.15 \\
\hline 5 & $\begin{array}{l}\text { I ask students to use the Internet to explore the TIMSS } \\
\text { samples. }\end{array}$ & Medium & .915 & 3.08 \\
\hline 6 & $\begin{array}{l}\text { I conduct classroom assessment activities to enrich students' } \\
\text { skills in handling TIMSS tests. }\end{array}$ & Medium & .890 & 3.48 \\
\hline 7 & $\begin{array}{l}\text { I am convinced that it is significance to train students on } \\
\text { TIMSS tests. }\end{array}$ & Medium & .970 & 3.81 \\
\hline 8 & $\begin{array}{l}\text { I realize the national importance for Jordan to have excellent } \\
\text { results in TIMSS. }\end{array}$ & High & .941 & 4.11 \\
\hline 9 & I have a special file for international assessment studies & Medium & 1.051 & 2.56 \\
\hline 10 & $\begin{array}{l}\text { I follow the changes in the level of Jordanian students } \\
\text { compared to the international results. }\end{array}$ & Medium & .944 & 2.87 \\
\hline 11 & $\begin{array}{l}\text { The instruction methods I use are compatible with the } \\
\text { TIMSS test patterns. }\end{array}$ & Medium & .833 & 3.41 \\
\hline 12 & $\begin{array}{l}\text { I make sure students solve questions and exercises in the } \\
\text { curriculum that require higher mental skills. }\end{array}$ & High & .861 & 4.33 \\
\hline \multirow[t]{2}{*}{13} & I have received a sufficient training on TIMSS tests. & Medium & 1.154 & 2.55 \\
\hline & Total & Medium & 0.612 & 3.38 \\
\hline
\end{tabular}

Most of the items of the first theme have a medium rate indicating that there is a deficient in science and mathematics teachers' role in their contributing to improve students' performance. This estimate is from the teachers themselves. In addition, it shows the teachers' lack of knowledge of the TIMSS test and the use of this knowledge in the teaching of their students. This is due to the commitment of most science and math teachers to the content of the textbook and not using additional sources of education. As there is strong correlation between teacher qualification and the performance of their students in the TIMSS tests, we conclude that teachers contribute significantly to the poor performance of Jordan's students in TIMSS tests, especially if we know that the experiences and qualifications of teachers in Jordan are varied. A large percent of teachers are low skilled, and practice traditional teaching and evaluation strategies, which is inconsistent with educational activities that help in improving the performance of students. 


\section{Reasons relate to the curriculum}

\section{Table 7}

Statistical Averages and Standard Deviations of the Sample in the Theme of the Reasons Related to the Curriculum

\begin{tabular}{lllll}
\hline Item & The second theme: Curriculum & Score & Standard Deviation & Mean \\
\hline 1 & $\begin{array}{l}\text { The construction and design of the curriculum meets the } \\
\text { needs of learners to pass the TIMSS test. }\end{array}$ & Medium & .631 & 3.42 \\
\hline 2 & $\begin{array}{l}\text { The curriculum of science and mathematics provides } \\
\text { elements of questions that require practical and mental skills. }\end{array}$ & High & .882 & 3.91 \\
\hline 3 & $\begin{array}{l}\text { The curriculum covers all aspects of the assessment process. } \\
\text { Medium }\end{array}$ & .835 & 3.67 \\
\hline 4 & $\begin{array}{l}\text { Activities that contribute to the development of the skills of } \\
\text { scientific thinking in the curriculum are varied. }\end{array}$ & High & .866 & 3.91 \\
\hline 5 & $\begin{array}{l}\text { The school curriculum offers a variety of teaching and } \\
\text { evaluation methods. }\end{array}$ & High & .856 & 3.66 \\
\hline 6 & $\begin{array}{l}\text { The curriculum stimulates teachers to develop their skills in } \\
\text { modern evaluation skills. }\end{array}$ & Medium & .889 & 3.92 \\
\hline 7 & $\begin{array}{l}\text { Curriculum questions take into account the overall level of } \\
\text { the student's achievement abilities (individual differences). }\end{array}$ & High & .939 & 2.21 \\
\hline 8 & $\begin{array}{l}\text { The curriculum includes the latest technology and supplies } \\
\text { that help improving students' performance in the TIMSS test. }\end{array}$ & Low & .980 & 3.55 \\
\hline
\end{tabular}

Table 7 shows the praise of the science and mathematics teachers in Jordan for the educational curricula and their distinctive characteristics that take into account most of the standards of planning educational curricula. Most of the items of the assessment were high or very close to high with a total of (3.55), which means that the contribution of the science and mathematics Jordanian curricula in the decline of the level of the student performance was low. The teachers of science and mathematics have emphasized that there is a great harmony between the learning activities in the curriculum and the requirements of the TIMSS test in terms of the diversity of learning and evaluation skills and the mental skills needed by the curriculum questions. The planning process of Jordanian curriculum undergoes several stages and in a context that involves several parties from the public and private sectors, as well as, the National Center for Human Resources Development (Eckert, 2011). Jordan's science and mathematics curricula are of high quality and designed according to modern strategies where several studies have shown that the structure of the Jordanian curriculum is close to the international standards in most countries of the world with high performance in the TIMSS test (Samida \& Grace, 2014). The Jordanian Ministry of Education, in cooperation with the National Center for Human Resources Development has planned and designed science and mathematics textbooks and teacher guides based on the results of the TIMSS analysis in previous courses (Ababneh, Al-Tweissi, Ababneh \& Abulibdeh, 2016). The concerned parties have designed special guides for science and mathematics teachers to deal with TIMSS tests and clarify their nature. However, the teachers noted that, the curriculum does not include modern technology and supplies to improve the performance of students in the TIMSS tests. 


\section{Reasons Relate to Student and Family:}

Table 8

Statistical Averages and Standard Deviations of the Sample of the Study Reasons for the Decline in Performance on the TIMSS study in the Theme of the Reasons for the Student

\begin{tabular}{lllll}
\hline Item & The third theme: Student & Score & $\begin{array}{l}\text { Standard } \\
\text { Deviation }\end{array}$ & Mean \\
\hline 1 & $\begin{array}{l}\text { Most students benefit from additional sources of information (such as } \\
\text { the Internet and others) to develop their assessment abilities. }\end{array}$ & Medium & .605 & 3.21 \\
\hline 2 & The student usually prepares himself for the TIMSS test. & Medium & 1.015 & 2.73 \\
\hline 3 & The student has experience in dealing with similar TIMSS questions. & Medium & .958 & 2.68 \\
\hline 4 & Parents have sufficient awareness about the importance of TIMSS tests. Poor & 1.203 & 1.91 \\
\hline 5 & $\begin{array}{l}\text { The cumulative weakness in the school subject does not affect the } \\
\text { student's retrieval of the necessary information in TIMSS tests. }\end{array}$ & Poor & 1.173 & 1.81 \\
\hline 6 & $\begin{array}{l}\text { Students desire to deal with questions that require higher mental } \\
\text { abilities. }\end{array}$ & Medium & 1.019 & 3.08 \\
\hline 7 & Most students recognize the national significance of TIMSS tests. & Medium & 1.005 & 2.58 \\
\hline 8 & Students are interested in obtaining high scores in TIMSS tests. & Medium & 1.082 & 2.74 \\
\hline & Total & Medium & 0.606 & 2.58 \\
\hline
\end{tabular}

Table 8 shows that Jordanian science and math teachers attributed the cause of the decline of Jordanian students' performance to students and their families more than the other reasons (teachers or curriculum). Teachers estimated that the contribution of students' characteristics and abilities to performance on the test was medium and close to low almost (2.58), and they showed there is a lack of interest in Jordan's students and their families in the TIMSS test. They often do not have the awareness of the significance of these tests for students or country. Teachers also have demonstrated the existence of a cumulative weakness in the students' skills. This greatly affects their performance in international tests showing the weakness of their skill in dealing with global testing as appropriate. Teachers have emphasized a very important issue - the inadequate attention by students to get high scores in the TIMSS test. This refers to the role of the inappropriate mechanisms followed in test application in Jordan. There is a difference in the average grade of science and math teachers in the three domains, although the degree of influence according to their point of view was medium for all domains as shown in Table 9.

Table 9

Arithmetic Averages for the Estimates of Science and Math Teachers of the Impact of the Three Domains Contributing to the Students' Performance on the TIMSS Test

\begin{tabular}{llll}
\hline Domain & Score & Standard Deviation & Mean \\
\hline Teacher & Medium & 0.612 & 3.38 \\
\hline Curriculum & Medium & 0.567 & 3.55 \\
\hline Student and family & Medium & 0.603 & 2.58 \\
\hline Total & Medium & 0.462 & 3.21 \\
\hline
\end{tabular}

Table 9 shows that the curriculum was more effective and has a positive effect on the performance of the students in Jordan on the TIMSS test with an average of (3.55) from 
the teachers' point of view. The teachers' contribution to improving their students' performance reached an average of (3.38), and the role of students skills and abilities was (2.58) as an average of their performance on the test. Therefore, the weakness of the skills and abilities of the students, as well as, their characteristics and their families are most influential in their decline in the TIMSS test. These results were harmonious with some studies (Hojo \& Oshio, 2010; Hanushek, 2006).

In order to identify the statistical significance of the differences between the arithmetic averages of the domains of influence on the decline in students' performance (teacher, curriculum, student, and family), the researchers used one-way Anova analysis after confirming the fulfilment of normality and homogeneity of the data as shown in Table 10.

Table 10

One-Way Analysis of Variance among Means

\begin{tabular}{llll} 
& Sum of squares & F & Sig \\
\hline Between groups & 47.62 & 67.296 & 0.00 \\
\cline { 1 - 2 } Within groups & 94.46 & & \\
\cline { 1 - 2 } Total & 142.08 & & \\
\hline
\end{tabular}

The table shows statistically significant differences between the estimates average of the members of the study for the reasons for the decline of the performance of Jordan students in the TIMSS tests and to determine the significance of differences for any of the averages, the Scheffe's test for Post Hoc Comparisons were applied and Table 11 was used for clarification.

Table 11

Scheffe's Test for Post Hoc Comparisons among the Domains Means

\begin{tabular}{lllll}
\hline Domain A & Domain B & Mean variances & Standard Error & Significance level \\
\hline Teacher: & Curriculum & $0.170-$ & 0.0886 & 0.159 \\
\cline { 2 - 5 } & Student and family & $0.793^{*}$ & 0.0886 & 0.000 \\
\hline Curriculum : & Student and family & $0.963 *$ & 0.0886 & 0.000
\end{tabular}

Table 11 shows that statistical differences often indicate the reasons associated with students are the most significant of their decline in the TIMSS test compared to the reasons for the teacher or the curriculum from the teachers 'point of view'. These estimates are due to many factors such as the feeling of the teachers in Jordan about the students' growing poor achievement, in addition to the decline of their motivation. This is in addition to students' lack of interest in the achievement of international tests because they do not affect their grades and do not motivate their families to encourage them to get high grades in these tests.

These results indicate the need for further research into the type of teacher-student relationships and the nature of the beliefs that teachers have in their minds towards their students.

\section{Reasons for Declining Performance Depending on a Set of Variables}

The second question of the study is concerned with determining the statistical significance of the differences in the estimates of the members of the study and their 
opinions about the reasons for the decline of the performance of Jordanian students in the TIMSS study according to the variables: (gender - specialization - work experience) .The following clarification of these variables:

\section{Gender}

Table (12) presents the average of the estimates of the members of the study sample according to their gender. As the table shows, there is compatibility of the views of teachers regarding the effect on the performance of the students in the domains of teacher and curriculum. However, there were differences between the estimates of males and females regarding the role of the students themselves in their performance where the estimates of male teachers that the reasons for the decline of students are more than the female teachers' estimate. It was found that the science and mathematics female teachers' estimates of the students' abilities and readiness to handle the TIMSS test have an average of (2.68), compared to an average of (2.40) by the male teachers. According to teachers, the difference in the averages is due to realistic indicators in most measurement results in Jordan, which indicated the higher achievement of female students compared to male students in most age groups. This view is consistent with the actual results of the performance of students in Jordan in most of the TIMSS tests.

Table 12

Average Rating of Study Members for the Domains of the Decline of Performance According to Their Gender

\begin{tabular}{lllc}
\hline Domain effect & Gender & Mean & Standard Deviation \\
\hline Teacher & Male & 3.39 & .511 \\
\cline { 2 - 4 } & Female & 3.37 & .663 \\
\hline \multirow{2}{*}{ Curriculum } & Male & 3.61 & .556 \\
\cline { 2 - 4 } & Female & 3.51 & .575 \\
\hline Student and family & Male & 2.40 & .602 \\
\cline { 2 - 4 } & Female & 2.68 & .586 \\
\hline
\end{tabular}

Specialization

When examining the differences in the estimates of the study members (teachers) according to the different disciplines (science - mathematics), table (13) shows that there are no differences in the estimates.

Table 13

Average Rating of Study Members for the Domains of the Decline of Performance According to Their Specialization

\begin{tabular}{llll}
\hline Domain effect & Specialization & Mean & Standard Deviation \\
\hline \multirow{2}{*}{ Teacher } & Science & 3.41 & .610 \\
\cline { 2 - 4 } & Mathematics & 3.35 & .618 \\
\cline { 2 - 4 } & Science & 3.61 & .624 \\
\cline { 2 - 4 } Student and family & Mathematics & 3.50 & .516 \\
\cline { 2 - 4 } & Science & 2.62 & .553 \\
\cline { 2 - 4 } & Mathematics & 2.56 & .646 \\
\hline
\end{tabular}

The consistency of estimates between science teachers and mathematics teachers regarding the reasons for the decline in Jordanian students' performance may be because 
science and mathematics learning skills are very consistent and similar. In most cases, students' knowledge and abilities in both subjects affect each other.

\section{Practical Experience}

To determine the impact of teachers 'teaching experience in assessing the reasons for the decline of the results of the students in the TIMSS study, the arithmetical averages and standard deviations of the evaluation scores were calculated as shown in Table 14.

Table 14

Average rating of study members for the domains of the decline of performance according to their practical experience

\begin{tabular}{llll}
\hline Domain effect & Work Experience & Mean & Standard Deviation \\
\hline \multirow{3}{*}{ Teacher } & 5 years $<$ & 3.3312 & .62704 \\
\cline { 2 - 4 } & $5-10$ & 3.3817 & .59881 \\
\cline { 2 - 4 } & 10 years $>$ & 3.4478 & .62143 \\
\cline { 2 - 4 } Curriculum & Total & 3.3821 & .61229 \\
\hline \multirow{5}{*}{ Student and family } & 5 years $<$ & 3.4757 & .60785 \\
\cline { 2 - 4 } & $5-10$ & 3.5769 & .52211 \\
\cline { 2 - 4 } & 10 years $>$ & 3.6295 & .56261 \\
\cline { 2 - 4 } & Total & 3.5528 & .56774 \\
\cline { 2 - 4 } & 5 years $<$ & 2.5625 & .54813 \\
\cline { 2 - 4 } & $5-10$ & 2.6010 & .76650 \\
\cline { 2 - 4 } & 10 years $>$ & 2.6116 & .51521 \\
\hline
\end{tabular}

Table 14 shows that there are no clear differences in the estimates of the study sample members regarding the reasons for the decline of the results of Jordanian students in the TIMSS according to their different teaching experiences as teachers. This may be due to the prevailing culture in the education sector in Jordan, which is teachers' blame for students that they are unwilling to learn. Teachers always attribute the decline in students' performance to the weakness of students themselves.

\section{CONCLUSION}

The results of the study showed the view of the teachers of science and mathematics in Jordan about the reasons for the decline in the performance of students on the TIMSS test locally. They attributed this decline to the weakness of the students with indicative statistical differences against the teachers' roles or the curriculum. As it turned to teachers, regardless of their expertise and specialization, they have agreed that the characteristics and abilities of students were the cause of this decline. Differences have also emerged between male and female teachers' evaluation, which revealed that the academic achievement of female students exceeds male .Hence, in the light of the study results; we recommend that the Ministry of Education in Jordan should first adopt strict and precise administrative procedures to participate in the TIMSS study to ensure appropriate preparation for students. Second, teachers should be trained on how to provide students with higher thinking skills. Third, it is necessary to propose strategies to ensure the perfect application of science and mathematics curricula in the 
instructional process. Fourth, to familiarize students with international tests, central and nationwide tests must be applied. Fifth, citizens of Jordan should be informed about the results in the TIMSS study to achieve public awareness and responsibility. Finally, further studies should be conducted to identify the nature of the teachers' beliefs towards their students and the reasons for those beliefs.

\section{REFERENCES}

Ababneh, A., Al-Tweissi, A., Ababneh,E., \& Abulibdeh,K.(2016). TIMSS 2015 ENCYCLOPEDIA - JORDAN. National Center for Human Resources Development.

Abu Libda, K. (2008). Jordanian National Report on the International Study of Mathematics and Science in 2007. National center for Human Resources Development. Amman. The Hashemite Kingdom of Jordan.

Chang, M., Singh, K., \& Mo, Y. (2007). Science engagement and science achievement: Longitudinal models using NELS data. Educational Research and Evaluation. 13 (4), 349-371.

Chetty R., Friedman, J. N., \& Rockoff J. E .(2014). Measuring the impacts of teachers I: Evaluating bias in teacher value-added estimates. American Economic Review, 104(9), 2593-2632.

Eckert, A. .(2011). Images of "self" and "other" in textbooks in Jordan, Egypt, Lebanon, and Oman. Educational sector, reforms, curricula and textbooks in selected MENA countries. Georg. Eckert-Institut fur international SchulbuchforschungBraunschweig .www.edumeres.net

Fuchs, T., \& Woessmann, L. (2004). What accounts for international differences in student performance? A re-examination using PISA data (IZA Discussion Paper 1287). Munich, Germany: Institute for the Study of Labor.

Ghamdi, H. ( 2010 ). Characteristics of the school in the high achievement countries ( China - Singapore) and low achievement ( Saudi Arabia ) in the International Mathematics and Science Examinations ( 2007- TIMSS ), unpublished master thesis , Umm Al Qura University, Makkah, Saudi Arabia .

Hanushek, E. A. (2006). School resources. In: Handbook of Economics of Education, Vol. 2 (eds.Hanushek, E.A. and Welch F.), pp. 865-908. Elsevier: Amsterdam.

Hanushek, E.A, Peterson, P.E., \& Woessmann, L. ( 2010). U.S. Math Performance in Global Perspective: How Well Does Each State Do at Producing High-Achieving Students? Cambridge, MA: Harvard's Program on Education Policy \& Governance, Harvard Kennedy School. http://www.hks.harvard.edu/pepg/PDF/Papers/PEPG10Hanushek PetersonWoessmann.pdf.

Hill, H.; Rowan B., \& Ball, D. (2005). Effects of teachers' mathematics knowledge for teaching on student achievement. American Educational Research Journal, 42(2), 371406. 
Hojo, M., \& Oshio, T. (2010). What factors determine student performance in East Asia? New evidence from TIMSS 2007. Technical Report. URL: http://hdl.handle.net/10086/18745.

Jaafari, F. (2010). Characteristics of students and their family in the high achievement countries (China - Singapore) and low achievement (Saudi Arabia) in TIMSS 2007, unpublished master thesis, Umm Al Qura University, Makkah, Saudi Arabia.

Ker, H. W. (2013). Trend Analysis on Mathematics Achievements: A Comparative Study Using TIMSS Data.Universal Journal of Educational Research 1(3): 200-203, 2013 DOI: 10.13189/ujer.2013.010309

Masakazu, H., \& Takashi, O. (2010). What factors determine student performance in East Asia? New evidence from TIMSS 2007.

Mullis, I. V. S., Martin, M. O., Minnich, C. A., Stanco, G. M., Arora, A., Centurino, V. A. S., \& Castle, C. E. (eds.) (2012). TIMSS 2011 Encyclopedia: Education Policy and Curriculum inMathematics and Science (Volumes 1 and 2). Chestnut Hill, MA: TIMSS $\&$ PIRLS International Study Center, Boston College.

Mullis, I. V. S., \& Martin, M. O. (Eds.). (2013). TIMSS 2015 assessment frameworks. Chestnut Hill,

MA:

TIMSS \& PIRLS International Study Center, Boston College

Mullis, I., Martin, M., \& Loveless, T.(2016). 20 Years of TIMSS International Trends in Mathematics and Science Achievement, Curriculum, and Instruction.TIMSS \& PIRLS International Study Center, Lynch School of Education, Boston College and International Association for the Evaluation of Educational Achievement (IEA)

Robinson, V. M. J., Lloyd, C. A., \& Rowe, K. J. (2008). The impact of leadership on student outcomes: An analysis of thedifferential effects of leadership types. Educational Administration Quarterly, 44 (5), 635-674.

Roseth, C. J., Johnson, D. W., \& Johnson, R. T. (2008). Promoting early adolescents' achievement and peer relationships: The effects of cooperative, competitive, and individualistic goal structures. Psychological Bulletin, 134 (2), 223-246.

Samida, H., \& Grace, N. (2014). Analysis of the Arab countries' international assessments results of TIMSS 2011 in. Arab League Educational, Cultural, and Scientific Organization. Arab Observatory for Education.

Shi, W., He, X., Wang, Y., Fan, Z., \& Guo, L. (2016). PISA and TIMSS Science Score, Which Clock is More Accurate to Indicate National Science and Technology Competitiveness? Eurasia Journal of Mathematics, Science \& Technology Education, 2016, 12(4), 965-974

Wigfield, A., \& Eccles, J. (2002). The development of competence beliefs, expectancies for success, and achievement values from childhood through adolescence. In A. Wigfield \& J. Eccles (Eds.), Development of achievement motivation (pp. 92-120). New York:Academic Press. 